\title{
Using longitudinal antibiotic point prevalence survey (PPS) to drive antimicrobial stewardship programmes in a Nigerian tertiary hospital
}

\author{
${ }^{*}$ Nwwajiobi-Princewill, P., ${ }^{1}$ Medugu, N., ${ }^{1}$ Gobel, M. , ${ }^{1}$ Aigbe, A., ${ }^{2}$ Versporten, A., \\ ${ }^{2}$ Pauwels, I., ${ }^{2}$ Goossens, H., and ${ }^{1}$ Iregbu, K. C. \\ ${ }^{1}$ Department of Medical Microbiology, National Hospital, Abuja, Nigeria \\ ${ }^{2}$ Laboratory of Medical Microbiology, Vaccine and Infectious Diseases Institute, \\ University of Antwerp, Antwerp, Belgium \\ *Correspondence to: princewill101@yahoo.com
}

\begin{abstract}
:
Background: Antimicrobial stewardship (AMS) provides a means of tackling antimicrobial resistance (AMR). Unfortunately, in Nigeria, like in some other low-and-middle-income countries (LMICs), AMS practice has been lacklustre due to poor institutional support amongst other factors. Efforts were made to address this situation by engaging with the management of National Hospital Abuja, Nigeria, using antibiotic prescription information obtained through repeated point prevalence survey.

Methodology: Two rounds of antibiotic PPS were conducted in 2015 and 2017 using the Global Point Prevalence Survey (G-PPS) format. Data were collected from all inpatients receiving antibiotics on the selected day of study, including patient characteristics, antimicrobial prescription details, laboratory results and information on a set of quality indicators. The data were uploaded to an online G-PPS application hosted at the University of Antwerp in Belgium for validation, analysis and reporting.

Results: The PPS data showed that hospital-wide antibiotic use prevalence increased from 58\% in 2015 to $61 \%$ in 2017. Surgical prophylaxis beyond 24 hours also increased from 88-90\% in 2015 to 100\% in 2017, and only minority of therapies were supported by laboratory input for diagnosis and monitoring; $22 \%$ in 2015 and $5 \%$ in 2017.

Conclusion: These results were used for evidence-based engagement with the management to formally support AMS activities in the hospital. Positive outcomes were the formal reconstitution and inauguration of AMS committee in 2018 as well as the issuance of a formal policy statement by the hospital in 2020 . The ease and free availability of Global PPS methodology makes it ideal in driving antimicrobial stewardship programme (ASP) in LMICs like Nigeria.
\end{abstract}

Keywords: Antibiotic stewardship checklist, institutional support, point prevalence survey, policy statement

Received Jan 10, 2021; Revised Mar 11, 2021; Accepted Mar 12, 2021

Copyright 2021 AJCEM Open Access. This article is licensed and distributed under the terms of the Creative Commons Attrition 4.0 International License <a rel="license" href="http://creativecommons.org/licenses/by/4.0/", which permits unrestricted use, distribution and reproduction in any medium, provided credit is given to the original author(s) and the source. Editor-in-Chief: Prof. S. S. Taiwo

\section{Utilisation d'une enquête longitudinale sur la prévalence ponctuelle des antibiotiques (PPS) pour conduire des programmes de gestion des antimicrobiens dans un hôpital tertiaire nigérian}

\author{
${ }^{* 1}$ Nwajiobi-Princewill, P., ${ }^{1}$ Medugu, N., ${ }^{1}$ Gobel, M., ${ }^{1}$ Aigbe, A., ${ }^{2}$ Versporten, A., \\ ${ }^{2}$ Pauwels, I., ${ }^{2}$ Goossens, H., et ${ }^{1}$ Iregbu, K. C. \\ ${ }^{1}$ Département de microbiologie médicale, Hôpital national, Abuja, Nigéria \\ ${ }^{2}$ Laboratoire de microbiologie médicale, Institut des vaccins et des maladies infectieuses, \\ Université d'Anvers, Anvers, Belgique \\ *Correspondance à: princewill101@yahoo.com
}

\begin{abstract}
Abstrait:
Contexte: La gestion des antimicrobiens (AMS) offre un moyen de lutter contre la résistance aux antimicrobiens (RAM). Malheureusement, au Nigéria, comme dans certains autres pays à revenu faible ou intermédiaire (PRFI), la pratique de la MGS a été médiocre en raison d'un soutien institutionnel insuffisant, entre autres facteurs. Des
\end{abstract}


efforts ont été faits pour remédier à cette situation en collaborant avec la direction de l'hôpital national d'Abuja, au Nigéria, en utilisant les informations sur les prescriptions d'antibiotiques obtenues grâce à une enquête ponctuelle répétée de prévalence.

Méthodologie: Deux séries d'antibiotiques PPS ont été menées en 2015 et 2017 en utilisant le format Global Point Prevalence Survey (G-PPS). Des données ont été recueillies auprès de tous les patients hospitalisés recevant des antibiotiques le jour sélectionné de l'étude, y compris les caractéristiques des patients, les détails de la prescription d'antimicrobiens, les résultats de laboratoire et les informations sur un ensemble d'indicateurs de qualité. Les données ont été téléchargées sur une application en ligne G-PPS hébergée à l'Université d'Anvers en Belgique à des fins de validation, d'analyse et rapports.

Résultats: Les données PPS ont montré que la prévalence de l'utilisation d'antibiotiques à l'échelle de l'hôpital est passée de $58 \%$ en 2015 à $61 \%$ en 2017. La prophylaxie chirurgicale au-delà de 24 heures est également passée de 88 à $90 \%$ en 2015 à 100\% en 2017, et seule une minorité de thérapies a été soutenue par entrée de laboratoire pour le diagnostic et la surveillance; $22 \%$ en 2015 et $5 \%$ en 2017.

Conclusion: Ces résultats ont été utilisés pour un engagement fondé sur des données probantes avec la direction afin de soutenir officiellement les activités AMS à l'hôpital. Les résultats positifs ont été la reconstitution formelle et l'inauguration du comité AMS en 2018 ainsi que la publication d'une déclaration de politique formelle par I'hôpital en 2020. La facilité et la disponibilité gratuite de la méthodologie Global PPS la rend idéale pour conduire le programme de gestion des antimicrobiens (ASP) en PRFI comme le Nigéria.

Mots clés: liste de contrôle pour la gestion des antibiotiques, soutien institutionnel, enquête ponctuelle de prévalence, déclaration de politique

\section{Introduction:}

The role of organisational support is emphasised by the dedication of a section of both the WHO and CDC checklists of essential healthcare facility core elements for antimicrobial stewardship programme (AMS) to leadership, accountability and responsibilities $(1,2)$. In certain situations, the support may be impaired by the management setting up AMS or selecting teams without recourse to the internationally recognised guidelines. AMS, a recognised systematic strategy to prevent and control the emergence of antimicrobial resistance (AMR) is most effective when applied under a structured organisational arrangement $(3,4)$. The creation and sustenance of this structure is strongly dependent on robust organisational support for AMS and plays a major role in determining the outcome of AMS interventions $(4,5)$. Such organisational and management support includes formal recognition of the necessity to set up AMS committee, allocation of budget, and appointment of persons with requisite qualifications and experience to oversee AMS programme.

A common factor in low-and-middleincome-countries (LMICs) is the relatively low level of antimicrobial use (AMU) information and the related low level of AMS activity $(6,7,8)$. Evidence, scientifically obtained and analysed, is the best way to provide proof of a problem. In the case of AMS, the prevalence and pattern of antimicrobial prescription are means to convince institution management of the problem of AMR $(1,4,9,10,11)$ and engage in conversation on strategies for its containment, especially in the form of a formal policy committing to AMS $(4,5,6,8)$. This is further bolstered when such scientific evidence is from within the institution.

Periodic assessment of antimicrobial prescription using PPS presents a simple, objective and comprehensive methodology ( 1 , $4,10)$. This information can be analysed and the results communicated and disseminated to key stakeholders to drive AMS $(6,8)$. The aim of this study is to determine the antimicrobial prescription patterns among inpatients in the hospital through PPS and use this information to improve management support for AMS activity in National Hospital, Abuja, Nigeria.

\section{Materials and method:}

\section{Study setting}

This study was carried out in National Hospital, a 450-bed tertiary centre located in Abuja, Northcentral Nigeria. The hospital provides general services for adult (medical and surgical) and paediatric (medical and surgical) as well as a wide range of specialist diagnostic and intervention services including intensive care, trauma, oncology, and haematology among others.

\section{Method of PPS}

Two rounds of antibiotic PPS were conducted in 2015 and 2017 using Global-PPS format developed by the University of Antwerp (www.global-pps.com). Briefly, AMS data were collected from all inpatients on ward admission at 8:00 hours on the selected days of study in 2015 and 2017, but surgical wards were not surveyed on Mondays and Fridays, and all patients admitted after 08.00hrs were excluded from the survey.

All inpatients on the day of the survey formed the denominator while all inpatients who had any antimicrobial treatment at the time of the survey formed the numerator. Information was gathered on antimicrobial use including prescription, indication and route of intake. Other information collected included but not limited to; age, gender, diagnosis, stop/review date, adherence to guidelines and laboratory results. The data were entered into 
the G-PPS online application software of the University of Antwerp in Belgium for analysis.

Measurement of AMS activity in the hospital The level of AMS activity in the hospital was objectively assessed annually from 2017 to 2020 using an AMS assessment toolkit adapted from the WHO and CDC checklists of essential healthcare facility core elements for AMS programmes $(1,2)$. This kit assigned scores for various elements of AMS activity grouped into sections covering 'leadership commitment', 'accountability and responsibilities', 'AMS actions', 'education and training', 'monitoring and surveillance', and 'reporting and feedback'. The values obtained were used to measure changes in AMS activity within the hospital.

\section{Results:}

\section{Antibiotic prevalence patterns:}

The PPS results across adult (medical, surgical, obstetrics and gynaecology) and paediatric (medical and surgical) wards, and intensive care unit (ICU) showed that there was a hospital wide increase in prevalence of antibiotic use from $58 \%$ in 2015 to $61 \%$ in 2017.
The pattern of surgical prophylaxis showed that prescription beyond 24 hours increased from $88-90 \%$ in 2015 to $100 \%$ in 2017. Only a minority of cases had evidence of targeted therapy based on laboratory input for diagnosis and monitoring with 22\% in 2015 and 5\% in 2017 (Table 1).

\section{Quality indicators:}

Majority of prescriptions were via the parenteral route in both years surveyed $(70 \%$ in 2015 and $82 \%$ in 2017) and 55\% and 50\% of patients were on two or more antibiotics in 2015 and 2017 respectively. Documentation of stop/review dates varied across the wards and ICU but in both years, it was lowest in the ICU (0\% in 2015 and $10 \%$ in 2017) while documentation of reasons for therapy in notes was highest in the same ICU (97\% in 2015 and $57 \%$ in 2017).

\section{AMS activity:}

The use of the toolkit adapted from the WHO AMS (1) showed that there was an improvement in AMS activity particularly in the sections covering 'leadership and commitment' and 'accountability and responsibilities' (Fig 1).

Table 1: Antibiotic prescription patterns in National Hospital, Abuja, Nigeria, 2015 and 2017

\begin{tabular}{|c|c|c|c|c|}
\hline \multirow{8}{*}{$\begin{array}{c}\text { Antibiotic } \\
\text { prevalence } \\
\text { patterns }\end{array}$} & & & \multicolumn{2}{|c|}{ Year of survey } \\
\hline & & & 2015 & 2017 \\
\hline & \multicolumn{2}{|c|}{ Antibiotic prevalence in percentage } & 58 & 61 \\
\hline & Targeted therapy in percentage & Hospital average & 22 & 5 \\
\hline & & Paediatrics & 10 & 5 \\
\hline & & Adults & 16 & 2 \\
\hline & Surgical prophylaxis $>24$ hours in & Surgical & 90 & 100 \\
\hline & & $O \& G$ & 88 & 100 \\
\hline \multirow[t]{8}{*}{ Quality indicators } & \multicolumn{2}{|c|}{ Parenteral route in percentage } & 70 & 82 \\
\hline & \multicolumn{2}{|c|}{ On $>2$ antibiotics in percentage } & 55 & 50 \\
\hline & Documentation of reason in notes in & Medical & 88 & 57 \\
\hline & & Surgical & 95 & 50 \\
\hline & & ICU & 97 & 57 \\
\hline & Documentation of stop/review dates & Medical & 45 & 22 \\
\hline & & Surgical & 82 & 42 \\
\hline & & ICU & 0 & 10 \\
\hline
\end{tabular}

$\overline{\mathrm{ICU}}=$ Intensive care unit; O \& G = Obstetrics \& Gynaecology 


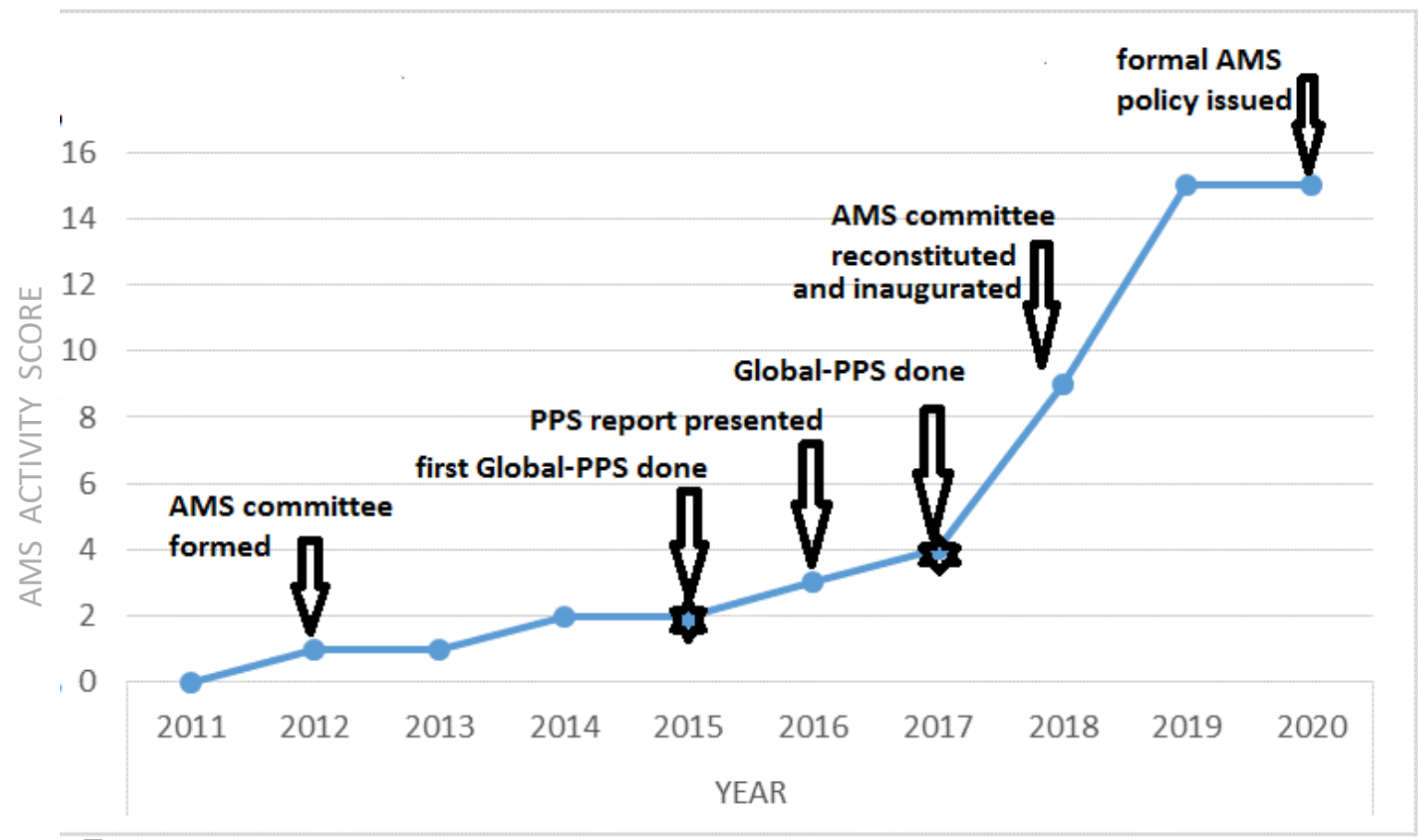

Institutional AMS activity milestone

Global-PPS done

Fig 1: Time-line of AMS activities following presentation of Global-PPS reports to National Hospital management

\section{Discussion:}

The antimicrobial prescription rates in our institution for 2015 and 2017 (58\% and $61 \%$ ) were higher than the worldwide average of $34.4 \%$ (12). Rates are significantly lower in countries where AMS activities have been actively pursued such as the Netherlands and Belgium with rates at $22.9 \%$ and $27.1 \%$ respectively $(13,14)$. This would suggest that antimicrobial misuse may be similarly high in this setting as it is linked to high prevalence rates (15). This was supported by the high levels of inappropriate surgical prophylaxis (88 -90\%) which is far higher than 40.6$86.3 \%$ worldwide average (12). On the other hand, prevalence of targeted therapy (22\% and $5 \%$ ), stop/review dates (range $0-82 \%$ ) and documented reasons for therapy in case notes ( $97 \%$ and $57 \%$ ) were comparable to the global average of $19.8 \%, 38.3 \%$ and $76.9 \%$ for these parameters respectively (12).

These results suggest the extent of poor antimicrobial utilisation in our institution and the need for a robust antimicrobial stewardship programme. While the problem exists in more developed climes, efforts to establish AMS in many LMICs more often suffer from lack of institutional support $(6,7)$. This has been demonstrated as major limitation to AMS activity in Nigerian healthcare institutions by Iregbu et al (16). In LMICs, AMS interventions are more effective when there is institutional support (17). An institution management does not necessarily set out to deny AMS the supports that it needs, however when there are competitions in the allocation of resources between overtly revenue generating hospital activities and non-revenue generating ones such as AMS, the latter usually gets short changed (8). Often AMS has failed to make a convincing case for itself and justify the resources it deserves from the management without which it cannot function $(5,8)$. Behavioural change has been demonstrated to be one of the most difficult things to achieve but persistent reinforcement of the message increases the chances for success $(11,18)$. This applies when trying to persuade managers and prescribers in healthcare providing institutions of the need to formally incorporate it into their healthcare policy and adopt new prescribing behaviours respectively (9).

The effectiveness of the AMS committee set up by our institution in 2012 was impaired by management's lukewarm support to AMS activities with no formal commitment or acknowledgement of AMR as an issue. Additionally, the committee was selected without adequate representation from key stakeholders. Information on antimicrobial prescription was needed to create local evidence for change. The results of our longitudinal Global-PPS were used for evidence-based engagement with the hospital management, which was done by presenting the PPS results to key policy makers and key stakeholders. Multiple opportunities were exploited to disseminate this information 
including management meetings and grand rounds. Positive outcomes of these were the formal reconstitution and inauguration of AMS committee in 2018.

The management of the hospital used internationally accepted criteria in selecting the AMS committee makeup and clear terms of reference were issued. The current committee is multidisciplinary with key stakeholders under a qualified leadership of a consultant microbiologist with infectious disease training, and physicians, pharmacist and nurse as members. This is in line with recommended best practice (1). Additionally, office space was provided, and significantly, the AMS committee has formed a collaboration with the infection prevention and control (IPC) team. Furthermore, the hospital charged a team made up of upper management and experts experienced in AMS, with creating a policy statement on AMS in 2019. This document was reviewed and released by the top management as a formal policy statement in early 2020. This is one measure recommended by MacDougall and Polk to improve the chances of AMS achieving any measure of success (6).

\section{Conclusion:}

Institutional support is more forthcoming when evidence of antimicrobial misuse within the system is provided and used to engage management. The ease of Global PPS methodology makes it ideal in driving ASP in LMICs like Nigeria. AMS professionals should undertake PPS and use this to enhance formal institutional support for AMS. As more institutions adopt AMS, it behoves healthcare personnel to ensure its success by carrying out PPS and using it as evidence for AMS.

\section{Acknowledgements:}

The authors acknowledge the contributions of the National Hospital Abuja AMS team during the point prevalence survey. The Global-PPS is coordinated at the University of Antwerp, Belgium and sponsored through an unrestricted grant given to them annually by bioMérieux.

\section{Conflicts of interest:}

Authors declare no conflicts of interest

\section{Previous publication:}

Oral presentation of this paper was made at the Virtual Conference of the Clinical Microbiology and Infectious Disease Society of Nigeria (CLIMIDSON) via Zoom on $26^{\text {th }}-27^{\text {th }}$ November 2020, and the abstract has been published in the conference program.

\section{References:}

1. Antimicrobial stewardship programmes in healthcare facilities in low- and middle-income countries. A practical toolkit. Geneva: World Health Organization; 2019

https://apps.who.int/iris/bitstream/handle/1066 5/329404/9789241515481-eng.pdf

2. The Core Elements of Hospital Antibiotic Stewardship Programs Antibiotic Stewardship Program Assessment Tool. Atlanta Ga: Centers for Disease Control and Prevention; 2019. https://www.cdc.gov/antibiotic-use/healthcare /pdfs/assessment-tool-P.pdf

3. Pulcini, C., Binda, F., Lamkang, A. S., et al. Developing core elements and checklist items for global hospital antimicrobial stewardship programmes: a consensus approach. Clin Microbiol Infect. 2019; 25 (1): 20-25 https://doi.org/10.1016/j.cmi.2018.03.033

4. Dyar, O. J., Huttner, B., Schouten, J., and Pulcini, C. What is antimicrobial stewardship? Clin Microbiol Infect. 2017; 23 (11): 793 - 798. https://doi.org/10.1016/j.cmi.2017.08.026

5. Mendelson, M., Morris, A. M., Thursky, K., and Pulcini, C. How to start an antimicrobial stewardship programme in a hospital. Clin Microbiol Infect. 2020; 26 (4): 447 - 453. https://doi.org/10.1016/j.cmi.2019.08.007

6. MacDougall, C., and Polk, R. E. Antimicrobial Stewardship Programs in Health Care Systems. Clin Microbiol Rev. 2005; 18 (4): 638-656. doi: 10.1128/CMR.18.4.638-656.2005

7. Kakkar, A. K., Shafiq, N., Singh, G., et al. Antimicrobial Stewardship Programs in Resource Constrained Environments: Understanding and Addressing the Need of the Systems. Front Publ HIth. 2020; 8: 140. doi:10.3389/fpubh.2020.00140

8. Hijazi, K., Joshi, C., and Gould, I. M. Challenges and opportunities for antimicrobial stewardship in resource-rich and resource-limited countries. Expert Rev Anti Infect Ther. 2019; 17 (10): 621634.doi:10.1080/14787210.2019.1640602

9. Paño-Pardo, J. R., Campos, J., Natera Kindelán, C., and Ramos, A. Initiatives and resources to promote antimicrobial stewardship. Enferm Infect Microbiol Clin. 2013; 31 Suppl 4:51-55. doi: $10.1016 /$ S0213-005X(13)70133-2L

10. Zarb, P., and Goossens, H. European Surveillance of Antimicrobial Consumption (ESAC): value of a point-prevalence survey of antimicrobial use across Europe. Drugs. 2011; 71 (6): 745 - 755. doi:10.2165/11591180-000000000-00000

11. Shah, R., and Shah, P. Antimicrobial stewardship in institutions and office practices. Indian J Pediatr. 2008; 75 (8): 815-820.

doi: $10.1007 / \mathrm{s} 12098-008-0153-z$

12. Versporten, A., Zarb, P., Caniaux, I., et al. Antimicrobial consumption and resistance in adult hospital inpatients in 53 countries: results of an internet-based global point prevalence survey. Lancet 2018; 6 (6): E619 - E629 https://doi.org/10.1016/S2214-109X(18)30186-4

13. Willemsen, I, Groenhuijzen, A., Bogaers, D., et al. Appropriateness of Antimicrobial Therapy Measured by Repeated Prevalence Surveys. Antimicrob Agents Chemother. 2007; 51 (3): 864-867.doi:10.1128/AAC.00994-06.

14. Vandael, E., Latour, K., Goossens, H., et al. Point prevalence survey of antimicrobial use and healthcare-associated infections in Belgian acute care hospitals: results of the Global-PPS and ECDC-PPS 2017. Antimicrob Resist Infect Contr. 2020; 9: 13. https://doi.org/10.1186/s13756019-0663-7

15. Antimicrobial resistance. Fact sheet. Geneva: World Health Organization; 2018. https://www.who.int/en/news-room/factsheets-/detail/antimicrobial-resistance 
16. Iregbu, K. C., Nwajiobi-Princewill, P. I., Medugu, N., et al. Antimicrobial Stewardship Implementation in Nigerian Hospitals: Gaps and Challenges. Afr. J. Clin. Exper. Microbiol. 2021;22 (1):60-66

https://dx.doi.org/10.4314/ajcem.v22i1.8

17. Charani, E., Smith, I., Skodvin, B., et al Investigating the cultural and contextual determinants of antimicrobial stewardship programmes across low-, middle- and high- income countries- a qualitative study. PLoS One. 2019; 14(1): e0209847.

doi: $10.1371 /$ journal.pone.0209847

18. Lin, L., Alam, P., Fearon, E., and Hargreaves, J.

$\mathrm{R}$. Public target interventions to reduce the inappropriate use of medicines or medical procedures: a systematic review. Implement Sci. 2020; 15 (1): 90.

doi:10.1186/s13012-020-01018-7 